Check for updates

Cite this: RSC Adv., 2018, 8, 4172

Received 12th December 2017 Accepted 16th January 2018

DOI: $10.1039 / c 7 r a 13286 g$

rsc.li/rsc-advances

\section{Influence of solvent and lecithin in microencapsulation of fish oil by spray-drying}

\author{
Cristian Encina, ${ }^{a}$ Cristina Vergara, ${ }^{c}$ Gloria Márquez-Ruiz, ${ }^{b}$ Francisca Holgado, \\ Paz Robert ${ }^{\mathrm{a}}$ and Begoña Giménez (ID *d
}

Fish oil (FO) was encapsulated by conventional spray-drying (FO-W-Lec) and by ethanol spray-drying, with FO incorporated as an oil-in-ethanol emulsion (with lecithin as emulsifier, FO-EtOH-Lec) or as an oil-inethanol dispersion (without lecithin, $\mathrm{FO}-\mathrm{EtOH}$ ). $\mathrm{FO}-\mathrm{EtOH}-\mathrm{Lec}$ and $\mathrm{FO}-\mathrm{W}$ - $\mathrm{Lec}$ were obtained according to a central composite design, whereas $\mathrm{FO}-\mathrm{EtOH}$ was prepared under optimal conditions. The optimal FO/hydroxypropylcellulose ratio was 1:4 for all FO-systems, but the optimal inlet gas temperature was lower for $\mathrm{FO}-\mathrm{EtOH}$ and $\mathrm{FO}-\mathrm{EtOH}-\mathrm{Lec}\left(135^{\circ} \mathrm{C}\right)$ than for $\mathrm{FO}-\mathrm{W}$-Lec $\left(200{ }^{\circ} \mathrm{C}\right)$. The encapsulation efficiency (EE) for ethanol spray-drying ( $\mathrm{FO}-\mathrm{EtOH}-\mathrm{Lec}, 81.1 \%$ and $\mathrm{FO}-\mathrm{EtOH}, 80.4 \%$ ) was higher than conventional spray-drying (71.1\%). However, the FO stability was better for FO-EtOH-Lec, measured either by total oxidation compounds or by polymerization compounds. The FO released in aqueous models corresponded only to surface FO in all FO-systems, showing Fickian diffusion. Ethanol spraydrying is an alternative to conventional methods, increasing the EE values of FO. Furthermore, lecithin allows improving the FO stability when incorporated as an emulsifier in ethanol spray-drying.

\section{Introduction}

Fish oil (FO) is one of the main sources of long chain polyunsaturated omega-3 fatty acids (LC $\omega 3$-PUFA). These fatty acids, especially eicosapentaenoic acid (EPA, C20 : 5 w3) and docosahexaenoic acid (DHA, C22:6 63 ) are necessary in human nutrition because of their health benefits. EPA is associated with cardiovascular protection, reducing blood cholesterol and triglyceride levels, ${ }^{1}$ whereas DHA is related to the development and function of the nervous and visual system of humans and other mammals. ${ }^{2}$ The intake recommendations from the World Health and North Atlantic Treaty Organizations are 0.3-0.5 g day of EPA + DHA. However, the worldwide average consumption is currently below these levels. ${ }^{2}$ EPA and DHA can be obtained from plant sources rich in alpha-linolenic acid (ALA, C18 : $3 \omega 3$ ), but the conversion of ALA into EPA and DHA is low. ${ }^{3}$ For this reason, healthy or functional foods supplemented with

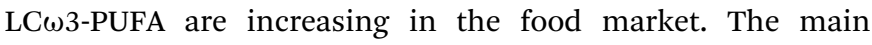
drawbacks of the incorporation of FO into foods are its low

\footnotetext{
${ }^{a}$ Departamento de Ciencia de los Alimentos y Tecnología Química, Facultad de Ciencias Quimicas y Farmacéuticas, Universidad de Chile, Santos Dumont 964, Independencia, Santiago, Chile

${ }^{b}$ Instituto de Ciencia y Tecnología de Alimentos y Nutrición (ICTAN-CSIC), José Antonio Novais 10, 28040 Madrid, Spain

'Fundación Fraunhofer Chile Research, Av. Mariano Sánchez Fontecilla 310 piso 14, Las Condes, Santiago, Chile

${ }^{d}$ Departamento de Ciencia y Tecnología de los Alimentos, Facultad Tecnológica, Universidad de Santiago de Chile, Av. Ecuador 3769, Estación Central, Santiago, Chile.E-mail: bego.gimenez@usach.cl
}

solubility in most food systems and its high susceptibility to oxidation. $^{4-7}$

Microencapsulation of FO with a coating material has been proposed as a strategy to retard lipid auto-oxidation, thus improving oil stability, prolonging its shelf life and limiting offflavours development. Furthermore, microencapsulation of FO allows its application in different food matrices, as well as controlled release of FO. $^{2,3,8}$ Conventional spray-drying is currently the most common method used to encapsulate FO. ${ }^{8}$ However, the encapsulation of FO requires a previous elaboration of oil-in-water emulsions as infeed that must be stable over a certain period prior to and during spray-drying., ${ }^{7,9-11}$

An alternative to conventional spray-drying is the use of solvents that would allow evaluating the effect of incorporating emulsifiers in the infeed system on the powder properties. To the best of our knowledge, this is the first study in the literature focused on this topic. Both the encapsulating agent and the FO must be at least dispersible in the solvent used to prepare the infeed system. Ethanol may be used as solvent in the microencapsulation of FO by spray-drying, since its use is permitted in food industry. In this sense, ethanol-water mixtures have been used as solvent in the microencapsulation of cromolyn sodium with lactose as encapsulating agent, in order to obtain powers with different crystalline degrees and to study its effect on the solid-state powder properties. ${ }^{12}$ Hydroxypropylcellulose, a partially-substituted poly(hydroxypropyl)ether of cellulose, was selected as encapsulating agent in this study due to its solubility in water and organic solvents. 
The objective of this work was to study the effect of the emulsifier (soy lecithin) and solvent (water and ethanol) in infeed systems for encapsulation of FO oil by spray-drying. FO microparticles were evaluated for encapsulation efficiency and oxidative stability of fish oil.

\section{Material and methods}

\subsection{Materials}

FO was donated by SPES S.A. (Santiago, Chile) and stored at $-18^{\circ} \mathrm{C}$. Hydroxypropylcellulose (KLUCEL $®$, HPC) was obtained from Laboratorios Saval S.A. (Santiago, Chile). Soy lecithin (Epikuron 145V) was supplied by Blumos Ltda. (Santiago, Chile). Ethanol, hexane, chloroform, diethyl ether, hydrochloric acid, petroleum ether, acetic acid, acetone, iron sulfate heptahydrate, barium chloride dehydrate, ammonium thiocyanate and silica gel 60 were purchased from Merck (Santiago, Chile). Silica cartridges for solid-phase extraction (Sep-Pack Vac Silica $6 \mathrm{~cm}^{3} / 1 \mathrm{~g}$ columns) were supplied by Waters (Milford, USA). Tricosaenoic acid and monostearin (purity > 99\%) were purchased from Nu-Check-Prep (Elysian, USA). Tetrahydrofuran (HPLC grade) was supplied by Merck (Santiago, Chile).

\subsection{Methods}

2.2.1. Content of EPA and DHA in fish oil and FO-microparticles. Fatty acids methyl esters (FAME) were prepared according to AOAC. ${ }^{13}$ FAMEs were analyzed using a gas chromatograph (7890B, Agilent Technologies, USA), with a HP-88 fused-silica capillary column $(100 \mathrm{~m}, 0.25 \mathrm{~mm}$ i.d., $0.20 \mu \mathrm{m}$ film thickness) and a flame ionization detector. The injector and detector temperatures were $250{ }^{\circ} \mathrm{C}$. The oven temperature was set at $180{ }^{\circ} \mathrm{C}$ for $32 \mathrm{~min}$, and increased to $230{ }^{\circ} \mathrm{C}$ at $20{ }^{\circ} \mathrm{C} \mathrm{min}^{-1}$, hold $32 \mathrm{~min}$. The injection volume was $1 \mu \mathrm{L}$. EPA and DHA were quantified using tricosaenoic acid (C23:0) as internal standard, according to AOCS. ${ }^{14}$ The results were expressed as mg EPA or DHA/g FO (1). The determination was performed in triplicate.

$$
\text { EPA or DHA }\left(\frac{\mathrm{mg}}{\mathrm{g}}\right)=\frac{A_{\mathrm{x}} \times W_{\mathrm{IS}} \times C F_{\mathrm{x}}}{A_{\mathrm{IS}} \times W_{\mathrm{S}} \times 1.04} \times 1000
$$

where $A_{\mathrm{x}}$ is the peak area of EPA or DHA; $A_{\mathrm{IS}}$ is the peak area of the internal standard; $C_{\mathrm{f}}$ is the correction factor (0.99 for EPA, 0.97 for DHA); $W_{\text {IS }}$ is the weight of the internal standard added to the sample $(\mathrm{mg}) ; W_{\mathrm{S}}$ is the weight of the sample $(\mathrm{mg})$ and 1.04 is the factor to express the results as mg EPA or DHA/g oil.

2.2.2. Preparation of FO microparticles by spray drying. The encapsulation of FO was performed by ethanol spray-drying and by conventional spray-drying (control), using HPC as encapsulating agent in both cases.

2.2.2.1. Preparation of FO microparticles by ethanol spraydrying. FO was incorporated to the infeed solution either as oilin-ethanol emulsion (with lecithin as emulsifier) or as oil-inethanol dispersion (without lecithin). FO microparticles by ethanol spray-drying with FO incorporated as oil-in-ethanol emulsion (FO-EtOH-Lec) were prepared according to a central composite $2^{2}+$ star design. The FO-HPC ratio $(1: 0.7-1: 4.3)$ and the inlet air temperature $\left(75-135{ }^{\circ} \mathrm{C}\right)$ were evaluated as independent variables, whereas the FO encapsulation efficiency (EE) was the dependent variable. The data were fitted to a second-order regression model, according to eqn (2).

$$
Y=\beta_{\mathrm{o}}+\sum_{i=1}^{2} \beta_{i} X_{i}+\sum_{i=1}^{2} \beta_{i i} X_{i}^{2}+\sum_{i=1}^{1} \sum_{j=i+1}^{2} \beta_{i j} X_{i} X_{j}
$$

where $Y$ was the response; subscripts $i$ and $j$ ranged from 1 to the number of variables $(n=2) ; \beta_{\mathrm{o}}$ was the intercept term; $\beta_{i}, \beta_{i i}$ and $\beta_{i j}$ values were linear, quadratic and cross-product coefficients, respectively; and $X_{i}$ and $X_{j}$ were the levels of independent variables.

The analysis of variance (ANOVA), test of lack of fit, and determination of regression coefficients were performed with the software Statgraphics (5.0 program, Manugistics Inc., Rockville, MA). Response surface methodology (RSM) was applied to maximize the response variable.

The FO-EtOH-Lec infeed solution (100 g) was prepared as follows: lecithin $(0.6 \mathrm{~g})$ was dispersed in ethanol $(12.5 \mathrm{~g})$ at $40{ }^{\circ} \mathrm{C}$, using a magnetic stirrer (500 rpm for $20 \mathrm{~min}$ ). Subsequently, this dispersion was added to FO (2.5 g) and homogenized (PT 2100, Polytron, Kinematica AG, Switzerland) at $13000 \mathrm{rpm}$ for $3 \mathrm{~min}$. HPC (1.7-10.8 g) was dispersed in ethanol (82.7-73.6 g) and stirred in an orbital shaker by $12 \mathrm{~h}(200 \mathrm{rpm})$ (JSSI-100C, JSR, Korea). Fish oil-in-ethanol emulsion was added to the HPC solution and homogenized at $19000 \mathrm{rpm}$ for $3 \mathrm{~min}$ (Polytron PT 2100, Kinematica AG, Switzerland). The droplet size of the FO-EtOH-Lec infeed solution was determined using a Malvern Mastersizer 2000 particle size analyzer (Malvern Instrument Ltd., Worcestershire, UK), with a He-Ne laser $(\lambda=$ $633 \mathrm{~nm}$ ) and a measurement range 0.01-2000 $\mu \mathrm{m}$. Six measurements were performed and the results were expressed as the average of the volume average diameter $\left(D_{(4,3)}\right)$.

FO microparticles by ethanol spray-drying with FO incorporated as oil-in-ethanol dispersion (FO-EtOH) were prepared according to optimal conditions (inlet air temperature of $135^{\circ} \mathrm{C}$ and FO-HPC ratio of $1: 3$ (submitted)). Briefly, ethanol (12.5 g) at $40{ }^{\circ} \mathrm{C}$ were added to $\mathrm{FO}(2.5 \mathrm{~g})$ and homogenized at $13000 \mathrm{rpm}$ for 3 min (Polytron PT-2100, Kinematica AG, Switzerland). HPC (7.5 g) was dispersed in ethanol $(77.5 \mathrm{~g})$ and stored at room temperature for $12 \mathrm{~h}$ with orbital shaking (200 rpm) (JSSI-100C, JSR, Korea). Fish oil-in-ethanol dispersion was added with constant stirring to the HPC solution and homogenized at $19000 \mathrm{rpm}$ for $3 \mathrm{~min}$ (Polytron PT 2100, Kinematica AG, Switzerland).

2.2.2.2. Preparation of $F O$ microparticles by conventional spray-drying. In this case, FO was incorporated as oil-in-water emulsion (with lecithin as emulsifier) and FO microparticles (FO-W-Lec) were prepared according to a central composite $2^{2}+$ star design. The FO : HPC ratio $(1: 0.7-1: 4.3)$ and the inlet air temperature $\left(150-200{ }^{\circ} \mathrm{C}\right)$ were evaluated as independent variables, and the $\mathrm{EE}$ of FO was the dependent variable. The data were fitted to a second-order regression model, according to eqn (2). The ANOVA, test of lack of fit, and determination of regression coefficients were performed with the software Statgraphics (5.0 program, Manugistics Inc., Rockville, MA). RSM was used to maximize the response variable. 
The FO-W-Lec infeed solution (100 g) was prepared as follows: lecithin $(0.6 \mathrm{~g})$ was dispersed in water $(30 \mathrm{~g})$ at $40{ }^{\circ} \mathrm{C}$ using a magnetic stirrer at $500 \mathrm{rpm}$ for $20 \mathrm{~min}$. These dispersions were added to FO (2.5 g), and homogenized with a high speed blender (26 $300 \mathrm{rpm}$ for $3 \mathrm{~min}$ ). HPC (1.7-10.8 g) was dispersed in water (65.7-56.6 g) and stirred for $12 \mathrm{~h}$ in an orbital shaker at $200 \mathrm{rpm}$ (JSSI-100C, JSR, Korea). Fish oil-in-water emulsion was added to the HPC solution and homogenized at $19000 \mathrm{rpm}$ for $3 \mathrm{~min}$ using a rotor-stator blender. The droplet size of the FO-W-Lec infeed solution was determined as described for FO-EtOH-Lec in 2.2.2.1.

2.2.3. Spray-drying. Conventional and ethanol infeed systems were fed into a laboratory scale spray-dryer (B-290 mini spray-dryer Büchi, co-current form, Switzerland). The operational conditions were: spray gas flow, $600 \mathrm{~L} \mathrm{~h}^{-1}$; gas flow rate (aspirator), $35 \mathrm{~m}^{3} \mathrm{~h}^{-1}$; feed flow (peristaltic pump); $1 \mathrm{~mL} \mathrm{~min}^{-1}$ for both conventional and ethanol methods. Air was used as drying gas in FO-W-Lec. However, in the case of FO-EtOH-Lec and FO-EtOH systems, nitrogen was used as drying gas and the B-290 mini spray-dryer was linked to mobile unit inert loop B-295 (Büchi, Switzerland). The powders were stored at $-18{ }^{\circ} \mathrm{C}$.

\subsubsection{Encapsulation efficiency and yield of fish oil}

2.2.4.1. Surface FO determination. Microparticle powders $(2 \mathrm{~g})$ were dispersed in petroleum ether $(20 \mathrm{~mL})$, stirred for $1 \mathrm{~min}$ at room temperature and filtered with anhydrous sodium sulfate. The solvent was removed using rotatory evaporator (R-100 Büchi, Switzerland) at $40{ }^{\circ} \mathrm{C}$ until constant weight.

2.2.4.2. Total FO determination. The coating material structure of the microparticles was completely destructed by the following procedure: microparticle powders $(0.6-1 \mathrm{~g})$ were dissolved in ethanol $(20 \mathrm{~mL})$. For oil extraction, a washing was performed with distilled water $(5 \mathrm{~mL})$ and hexane $(5 \mathrm{~mL})$, stirred for $1 \mathrm{~min}$ at room temperature, sonicated for $5 \mathrm{~min}$ and centrifuged at $4000 \mathrm{rpm}$ for $4 \mathrm{~min}$. The supernatant (organic phase) was separated and the washing was repeated three times. The supernatants were joined and the solvent was removed using rotatory evaporator at $40{ }^{\circ} \mathrm{C}$ until constant weight.

Encapsulation efficiency (EE) and yield $(Y)$ of fish oil were calculated using eqn (3) and (4).

$$
\begin{aligned}
& \mathrm{EE}(\%)= \\
& \frac{\text { total FO in the powder }(\mathrm{g})-\text { surface FO in the powder }(\mathrm{g})}{\text { total FO in the powder }(\mathrm{g})} \\
& \times 100
\end{aligned}
$$$$
Y(\%)=\frac{\text { powder after the spray drying }(\mathrm{g})}{\text { solids in the feed solution }(\mathrm{g})} \times 100
$$

2.2.5. Microparticles characterization. Water activity $\left(a_{\mathrm{w}}\right)$ was determined by the dewpoint method using a Hygrolab 2 (Rotronic, USA) at $20 \pm 0.3{ }^{\circ} \mathrm{C}$. Hygroscopicity was determined according to Cai and Corke. ${ }^{15}$ The moisture content was determined with an infrared moisture analyzer (PMC50, Radwag, USA).
The particle size and size distribution were determined by light scattering using a laser diffraction particle size analyzer (LV 950-V2 Horiba, Kyoto, Japan). The microparticles were dispersed in recirculating water, and the results were expressed as $D_{(4,3)}$. The outer structures of all the FO microparticle systems were examined by scanning electron microscopy (SEM). The microparticles were coated with gold/palladium, using a Varian Vacuum Evaporator PS 10E and analyzed using a LEO 1420VP SEM (LEO Electron Microscopy Ltd., UK) operated at $20 \mathrm{kV}$. The images were collected digitally (EDS 7424 software, Oxford Instruments, UK).

2.2.6. Release of fish oil from FO microparticles. Release of FO from microparticles obtained under optimal conditions (FO-W-Lec, FO-EtOH, FO-EtOH-Lec) was evaluated in aqueous models (phosphate buffer pH 6.5 to simulate milk and acetate buffer $\mathrm{pH} 4.6$ to simulate yogurt). FO-microparticles ( $5 \mathrm{~g})$ in cellulose filter bags were placed into glass bottles $(250 \mathrm{~mL})$ with buffer pH 4.6 or pH $6.5(100 \mathrm{~mL})$, stoppered and stored at $30 \pm$ $2{ }^{\circ} \mathrm{C}$ in an orbital shaker at $55 \mathrm{rpm}$ (JSSI-100C, JSR, Korea) in the dark. Aliquots $(15 \mathrm{~mL})$ were removed (triplicate) at specific time intervals, and the initial volume was maintained by the addition of the corresponding buffer. FO was extracted three times with hexane by liquid-liquid extraction. The supernatants were joined and the solvent was removed using a rotatory evaporator at $40{ }^{\circ} \mathrm{C}$ until constant weight.

The data were fitted to Higuchi Kinetic model, ${ }^{16}$ according to eqn (5):

$$
\frac{M_{t}}{M_{\infty}}=k \times t^{1 / 2}
$$

$M_{t}$ is defined as the quantity of FO released at any time $t$, and $M_{\infty}$ is the initial FO loading. The release rate constants $(k)$ were obtained from the slope of a plot $M_{t} / M_{\infty}$ versus (time) $)^{1 / 2}$.

2.2.7. Storage stability assays of FO microparticles. Open Petri dishes $(10 \mathrm{~cm})$ with $2.5 \mathrm{~g}$ of FO microparticles obtained under optimal conditions (FO-W-Lec, FO-EtOH-Lec, FO-EtOH) were stored at $40 \pm 1{ }^{\circ} \mathrm{C}$ in a forced-air oven (BE 500, Memmert, Germany) in the dark. Petri dishes (in triplicate) were removed at specific time intervals for analyses. Additionally, samples were kept refrigerated in the dark at $5 \pm 1{ }^{\circ} \mathrm{C}$ and analyzed after 5 months.

2.2.7.1. Extraction of oil from microparticles during storage. Surface oil was extracted following the procedure detailed in 2.2.4. For extraction of the encapsulated oil from the microparticles devoid of surface oil, $2 \mathrm{~g}$-samples were rubbed in a mortar with $0.5 \mathrm{~mL}$ water to obtain a clotted mass. Then, $2.5 \mathrm{~g}$ $\mathrm{Na}_{2} \mathrm{SO}_{4}$ were added and the mixture was rubbed again until a granular mass was obtained. The oil was extracted with diethyl ether $(3 \times 20 \mathrm{~mL})$. After filtration through anhydrous $\mathrm{Na}_{2} \mathrm{SO}_{4}$, the solvent was removed using a rotatory evaporator at $40{ }^{\circ} \mathrm{C}$ and the sample dried until constant weight under stream of nitrogen. ${ }^{17}$

2.2.7.2. Determination of polar compounds. Formation and distribution of polar compounds in both surface FO and encapsulated FO was carried out by solid phase extraction followed by high performance size exclusion chromatography 
analysis, described in detail, including precision, accuracy and recovery data. ${ }^{18}$

2.2.7.2.1. Solid phase extraction (SPE). The polar fraction of both surface and encapsulated FO in each system was isolated by SPE. For this, extracted oil (50 $\mathrm{mg}$ ) was dispersed in hexane $(2 \mathrm{~mL})$ and separated into two fractions by Sep-Pack Vac Silica columns $\left(6 \mathrm{~cm}^{3} / 1 \mathrm{~g}\right)$, previously conditioned with petroleum ether: diethyl ether $(15 \mathrm{~mL} ; 90: 10, \mathrm{v} / \mathrm{v})$. The first fraction (unoxidized triacylglycerols) was eluted with petroleum ether: diethyl ether (15 mL; $90: 10, \mathrm{v} / \mathrm{v})$. The second fraction (containing triacylglycerol polymers, triacylglycerol dimers, oxidized triacylglycerol monomers, diacylglycerols, free fatty acids and polar unsaponifiable matter) was eluted with diethyl ether $(25 \mathrm{~mL})$. For quantitative purpose, monostearin $(1 \mathrm{mg})$ was used as internal standard. The separation efficiency was checked by thin layer chromatography, using a silica plate and hexane : diethyl ether : acetic acid (60:40:2) as elution solvent, and revealed with iodine vapour.

2.2.7.2.2. High performance size exclusion chromatography (HPSEC). The separation and quantification of the polar compounds was performed by HPSEC, using a chromatograph equipped with a Waters 510 pump (Waters, Milford, USA), a Rheodyne $7725 \mathrm{i}$ injector (10 $\mu \mathrm{L}$ sample loop), and a refractive index detector (HP 1037 A, Agilent Technologies, Palo Alto, USA). The separation was performed on 100 and $500 \AA$ columns $(25 \mathrm{~cm} \times 0.77 \mathrm{~cm}$ i.d.) packed with porous, highly cross-linked styrene-divinylbenzene copolymers (film thickness $5 \mu \mathrm{m}$ ) (Agilent Technologies, Palo Alto, USA) connected in series, with tetrahydrofuran $\left(1 \mathrm{~mL} \mathrm{~min}^{-1}\right)$ as the mobile phase.

2.2.8. Statistics. All the results were reported as mean \pm standard deviation (SD). One-way ANOVA was applied to determine the statistical differences among systems, using Statgraphics, Version 7.0 (Manugistic Inc., Statistical Graphics Corporation, Rockville, MD).

\section{Results and discussion}

\subsection{Fish oil microparticles}

A central composite design was applied to evaluate the effect of the FO/HPC ratio $\left(X_{1}\right.$, formulation variable) and the inlet gas temperature $\left(X_{2}\right.$, process variable) on the encapsulation of FO by ethanol (FO-EtOH-Lec) and conventional spray-drying (FO$\mathrm{W}$-Lec), respectively. Table 1 shows the experimental design for both spray-drying systems. The EE of FO was higher in FOEtOH-Lec, with values ranging from $41 \%$ to $85 \%$, whereas the FO-W-Lec systems showed values of EE between $17.1 \%$ and $72.3 \%$. The FO recovery was high (close 100\%) for both spraydrying systems, and thereby this variable was not considered as response variable.

The ANOVA for the EE of FO-microparticle systems by ethanol and conventional spray-drying is shown in Table 2. For FO-EtOH-Lec, the EE of FO was significantly ( $p \leq 0.05)$ affected by the linear and quadratic forms of $\mathrm{FO} / \mathrm{HPC}$ ratio and the linear form of the inlet gas temperature; whereas in FO-W-Lec, the EE of FO was significantly affected by the linear and quadratic forms of FO/HPC ratio and the linear and quadratic
Table 1 Experimental design for the microencapsulation of fish oil by spray-drying $^{a}$

\begin{tabular}{|c|c|c|c|}
\hline Run/System & Ratio FO/HPC $\left(X_{1}\right)$ & $\begin{array}{l}\text { Inlet gas } \\
\text { temperature }\left({ }^{\circ} \mathrm{C}\right)\left(X_{2}\right)\end{array}$ & $\mathrm{EE}(\%)$ \\
\hline \multicolumn{4}{|l|}{ FO-EtOH-Lec } \\
\hline 1 & $1: 1(-1)$ & $80(-1)$ & $47.8 \pm 1.2$ \\
\hline 2 & $1: 1(-1)$ & $130(+1)$ & $48.0 \pm 1.3$ \\
\hline 3 & $1: 4(+1)$ & $80(-1)$ & $70.0 \pm 1.5$ \\
\hline 4 & $1: 4(+1)$ & $130(+1)$ & $81.0 \pm 0.5$ \\
\hline 5 & $1: 2.5(0)$ & $75(-1.21)$ & $70.0 \pm 0.3$ \\
\hline 6 & $1: 2.5(0)$ & $135(+1.21)$ & $77.0 \pm 1.3$ \\
\hline 7 & $1: 0.7(-1.21)$ & $105(0)$ & $41.0 \pm 0.2$ \\
\hline 8 & $1: 4.3(+1.21)$ & $105(0)$ & $85.0 \pm 0.7$ \\
\hline 9 & $1: 2.5(0)$ & $105(0)$ & $70.0 \pm 0.7$ \\
\hline 10 & $1: 2.5(0)$ & $105(0)$ & $72.0 \pm 2.0$ \\
\hline 11 & $1: 2.5(0)$ & $105(0)$ & $71.8 \pm 0.6$ \\
\hline 12 & $1: 2.5(0)$ & $105(0)$ & $75.3 \pm 0.1$ \\
\hline \multicolumn{4}{|l|}{ FO-W-Lec } \\
\hline 1 & $1: 1(-1)$ & $154(-1)$ & $21.5 \pm 1.6$ \\
\hline 2 & $1: 1(-1)$ & $196(+1)$ & $33.4 \pm 1.2$ \\
\hline 3 & $1: 4(+1)$ & $154(-1)$ & $52.6 \pm 3.1$ \\
\hline 4 & $1: 4(+1)$ & $196(+1)$ & $72.3 \pm 1.8$ \\
\hline 5 & $1: 2.5(0)$ & $150(-1.21)$ & $28.3 \pm 1.4$ \\
\hline 6 & $1: 2.5(0)$ & $200(+1.21)$ & $44.4 \pm 2.3$ \\
\hline 7 & $1: 0.7(-1.21)$ & $175(0)$ & $17.1 \pm 0.4$ \\
\hline 8 & $1: 4.3(+1.21)$ & $175(0)$ & $54.4 \pm 2.1$ \\
\hline 9 & $1: 2.5(0)$ & $175(0)$ & $32.8 \pm 0.9$ \\
\hline 10 & $1: 2.5(0)$ & $175(0)$ & $35.0 \pm 1.7$ \\
\hline 11 & $1: 2.5(0)$ & $175(0)$ & $31.0 \pm 1.2$ \\
\hline 12 & $1: 2.5(0)$ & $175(0)$ & $36.8 \pm 0.7$ \\
\hline
\end{tabular}

${ }^{a}$ FO: fish oil; HPC: hidroxypropylcelullose; EtOH: ethanol; Lec: lecithin; W: water; EE: encapsulation efficiency.

Table 2 ANOVA for encapsulation efficiency of $\mathrm{FO}-\mathrm{EtOH}-\mathrm{Lec}$ and FO-W-Lec systems ${ }^{a}$

\begin{tabular}{|c|c|c|c|c|}
\hline \multirow[b]{2}{*}{ Effect } & \multicolumn{2}{|c|}{ FO-EtOH-Lec } & \multicolumn{2}{|l|}{ FO-W-Lec } \\
\hline & Estimate & $p$-value & Estimate & $p$-value \\
\hline$X_{1}$ & 31.3039 & $0.0003^{*}$ & 33.236 & $0.0004^{*}$ \\
\hline$X_{2}$ & 5.67824 & $0.0430 *$ & 14.7458 & $0.0046^{*}$ \\
\hline$X_{1}^{2}$ & -16.6738 & $0.0044^{*}$ & 8.92571 & $0.0355^{*}$ \\
\hline$X_{2}^{2}$ & - & - & 9.74533 & $0.0283^{*}$ \\
\hline$X_{12}$ & - & - & - & - \\
\hline Lack of fit & & 0.1345 & & 0.1267 \\
\hline$R^{2}$ & 94.6 & & 94.9 & \\
\hline Adjusted $R^{2}$ & 92.6 & & 92.0 & \\
\hline
\end{tabular}

${ }^{a}$ FO: fish oil; W: water; EtOH: ethanol; Lec: lecithin; *significative ( $p \leq$ $0.05)$.

forms of the inlet gas temperature. The models explained over $92 \%$ of the variability ( $R^{2}$ adj. for d.f.) in EE for both FO-EtOHLec and FO-W-Lec systems (Table 2), with residual values below 6.0. The equations describing the effect of the independent variables on the EE of FO are the following:

$$
\begin{aligned}
\mathrm{EE}(\mathrm{FO}-\mathrm{EtOH}-\mathrm{Lec})= & 11.0527+28.9611 \times X_{1}+0.113565 \\
& \times X_{2}-3.70529 \times X_{1}{ }^{2}
\end{aligned}
$$




$$
\begin{aligned}
\mathrm{EE}(\mathrm{FO}-\mathrm{W}-\mathrm{Lec})= & 294.549+1.16123 \times X_{1}-3.5161 \times X_{2} \\
& +1.98349 \times X_{1}{ }^{2}+0.0110491 \times X_{2}{ }^{2}
\end{aligned}
$$

The surface response plots for both FO microparticles systems (Fig. 1) showed a maximum EE included in the experimental domain. Furthermore, the variation of the FO/HPC ratio had higher influence on the EE than that of the inlet gas temperature, and the highest values were found at FO/HPC ratios with higher HPC content. Thus, the optimal FO/HPC ratio was $1: 4$ for both FO-EtOH-Lec and FO-W-Lec systems, showing the same content of total solids in both cases. As shown in Fig. 1, the higher the encapsulating agent content, the higher EE of FO because the faster the formation of the dry crust over the oil droplets surface, leading to higher emulsion retention. ${ }^{8} \mathrm{FO} /$ encapsulating agent ratios from $1: 1$ to $1: 6$ have been reported in microencapsulation of FO by conventional spray-drying. ${ }^{19}$ However, to the best of our knowledge, this is the first study dealing with the microencapsulation of fish oil-inethanol emulsions by solvent spray-drying.

The inlet gas temperature showed a low effect on the EE of FO in the range of studied values. However, the extent of lipid oxidation can be influenced by the inlet gas temperature, and higher lipid oxidation would be expected with higher inlet gas temperatures. In the case of FO-W-Lec system, the optimal inlet gas temperature was $200{ }^{\circ} \mathrm{C}$, in the range reported in the literature for conventional spray-drying $\left(140-215^{\circ} \mathrm{C}\right) .{ }^{19}$ However, the optimal inlet gas temperature was lower for FO-EtOH-Lec and FO-EtOH systems $\left(135^{\circ} \mathrm{C}\right)$, attributed to the lower boiling point of ethanol.

\subsection{Characterization of fish oil microparticles}

Table 3 shows the characteristics of FO microparticles obtained under optimal conditions (FO-EtOH-Lec, FO-EtOH and FO-W-

A

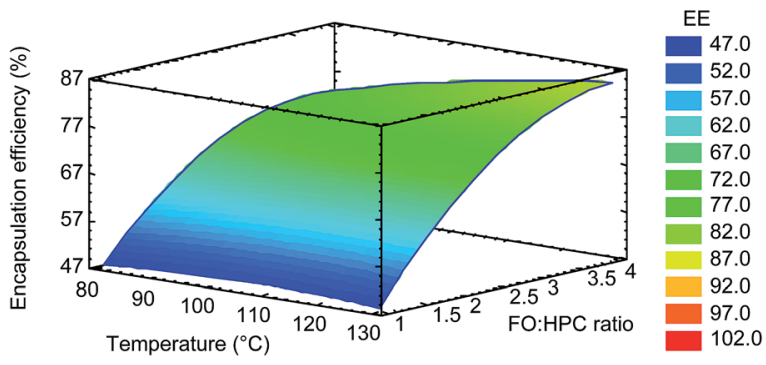

B

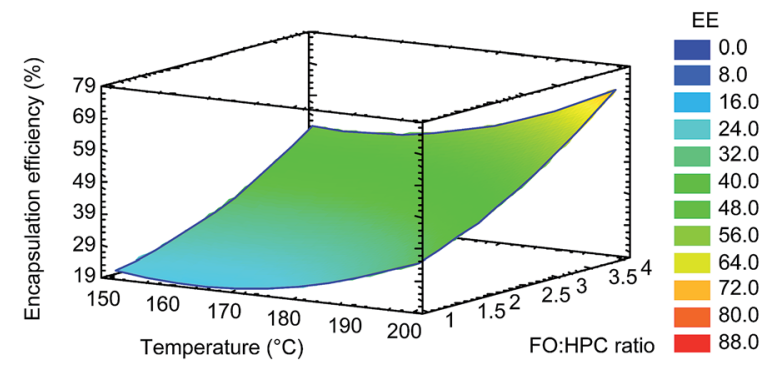

Fig. 1 Graphics of RSM for (A) FO-EtOH-Lec and (B) FO-W-Lec.
Table 3 Characterization of microparticles ${ }^{a}$

\begin{tabular}{llll}
\hline Parameters & FO-EtOH-Lec & FO-EtOH & FO-W-Lec \\
\hline FO/HPC ratio & $1: 4$ & $1: 4$ & $1: 4$ \\
Gas inlet temperature & 135 & 135 & 200 \\
$\left({ }^{\circ} \mathrm{C}\right)$ & & & \\
FO EE $(\%)$ & $81.1 \pm 3.7 \mathrm{a}$ & $80.4 \pm 0.6 \mathrm{a}$ & $71.1 \pm 1.0 \mathrm{~b}$ \\
Total FO $\left(\mathrm{mg} \mathrm{g}^{-1}\right)$ & $194.5 \pm 1.5 \mathrm{a}$ & $200.0 \pm 0.6 \mathrm{a}$ & $198.4 \pm 0.5 \mathrm{a}$ \\
Surface FO $\left(\mathrm{mg} \mathrm{g}^{-1}\right)$ & $36.1 \pm 2.0 \mathrm{~b}$ & $39.2 \pm 3.4 \mathrm{~b}$ & $57.3 \pm 2.0 \mathrm{a}$ \\
EPA $(\mathrm{mg}$ EPA $/ \mathrm{g}$ & $24.8 \pm 1.0 \mathrm{a}$ & $25.4 \pm 1.2 \mathrm{a}$ & $24.7 \pm 0.6 \mathrm{a}$ \\
microparticle) & & & \\
DHA(mg DHA $/ \mathrm{g}$ & $13.2 \pm 0.6 \mathrm{a}$ & $15.6 \pm 0.8 \mathrm{a}$ & $15.2 \pm 0.9 \mathrm{a}$ \\
microparticle) & & & \\
Yield $(\%)$ & $53.0 \pm 1.2 \mathrm{a}$ & $53.5 \pm 1.8 \mathrm{a}$ & $30.9 \pm 3.9 \mathrm{~b}$ \\
Moisture $(\%)$ & $4.9 \pm 0.4 \mathrm{a}$ & $4.5 \pm 0.2 \mathrm{a}$ & $5.0 \pm 0.1 \mathrm{a}$ \\
$a_{\mathrm{w}}$ & $0.25 \pm 0.01 \mathrm{~b}$ & $0.33 \pm 0.01 \mathrm{a}$ & $0.29 \pm 0.00 \mathrm{ab}$ \\
Hygroscopicity $(\mathrm{g} / 100 \mathrm{~g})$ & $25.5 \pm 0.1 \mathrm{a}$ & $22.4 \pm 0.6 \mathrm{~b}$ & $24.4 \pm 0.3 \mathrm{a}$ \\
Particle size $D_{(4,3)}(\mu \mathrm{m})$ & $1.80 \pm 0.07 \mathrm{~b}$ & $0.53 \pm 0.01 \mathrm{c}$ & $2.43 \pm 0.15 \mathrm{a}$
\end{tabular}

${ }^{a}$ FO: fish oil; EtOH: ethanol; Lec: lecithin; W: water; EE: encapsulation efficiency. Different letters show significantly different between systems $(p \leq 0.05)$.

Lec). The presence of an oil-in-ethanol emulsion stabilized by lecithin in the infeed system (FO-EtOH-Lec) did not have any significant effect on EE, in relation to FO-EtOH system, showing similar ( $p>0.05$ ) EE of FO (81.1\% and 80.4\%, respectively), in spite of the encapsulation mechanism could be different. When a fish oil emulsion is encapsulated by spray-drying the encapsulation efficiency represents the fish oil emulsion retention within the microparticles, whereas in the case of absence of lecithin in the infeed system, the encapsulation mechanism involves the direct interaction between HPC and triglycerides of FO mainly by hydrophobic forces and van der Waals interactions. Although the FO-W-Lec (control) and FO-EtOH-Lec systems were prepared with different solvents (water and ethanol, respectively), the EE was higher in FO-EtOH-Lec (Table 3 ), in spite of the encapsulation mechanism is based on the emulsion retention in both cases. This behavior may be explained by the lower droplet size of the infeed (FO-emulsion with HPC) in the case of FO-EtOH-Lec $\left(D_{(4,3)}=0.48 \mu \mathrm{m}\right)$, when compared to FO-W-Lec $\left(D_{(4,3)}=0.97 \mu \mathrm{m}\right)$, attributed to lower dielectric constant of ethanol (25.8 vs. 81.1 for water) and/ or the lower interfacial tension at oil-EtOH interface $(2.4 \mathrm{mN}$ $\mathrm{m}^{-1}$ reported in a $95 \%$ ethanol-oil system $)^{20}$ compared to that of oil-water systems $\left(19.0-24.5 \mathrm{mN} \mathrm{m}^{-1}\right) .{ }^{21}$

The total FO content in the microparticles containing lecithin (FO-EtOH-Lec and FO-W-Lec) and without lecithin (FOEtOH) was similar $\left(p>0.05\right.$ ), around $200 \mathrm{mg} \mathrm{g}^{-1}$ (Table 3). The total FO content for conventional spray-dried microparticles is variable, and both higher and lower values than those obtained in this study have been reported (108-119 $\mathrm{mg} \mathrm{g}^{-1} ;$; $^{22}$ 244-492 $\mathrm{mg} \mathrm{g}^{-1}$ (ref. 6)). Furthermore, similar behavior to total FO content was obtained for the content of EPA and DHA, with similar values in all the systems ( $p>0.05$; Table 3 ). In this study, one gram of FO-microparticles provides on average $39 \mathrm{mg}$ of EPA + DHA, which is approximately $7.8-13 \%$ of the recommended daily dose (0.3-0.5 g of EPA + DHA per day). All the 
systems (FO-W-Lec, FO-EtOH, FO-EtOH-Lec) showed similar moisture content $(p>0.05)$ with values ranging from 4.5 to $5.0 \%$, whereas $a_{\mathrm{w}}$ values ranged from 0.25 to 0.33 , ensuring the microbiological stability of the microparticles. The hygroscopicity was also similar $(p>0.05)$ in all the systems studied (Table 3 ), because HPC was used as encapsulating agent in all of them.
Fig. 2(A.1-C.1), shows the SEM photographs and particle size distributions of FO-microparticle powders (FO-EtOH-Lec, FOEtOH and FO-W-Lec) obtained under optimal conditions. All the microparticles showed spherical shapes with smooth surface, although a higher proportion of dented microparticles was found in FO-W-Lec system, which may be attributed to
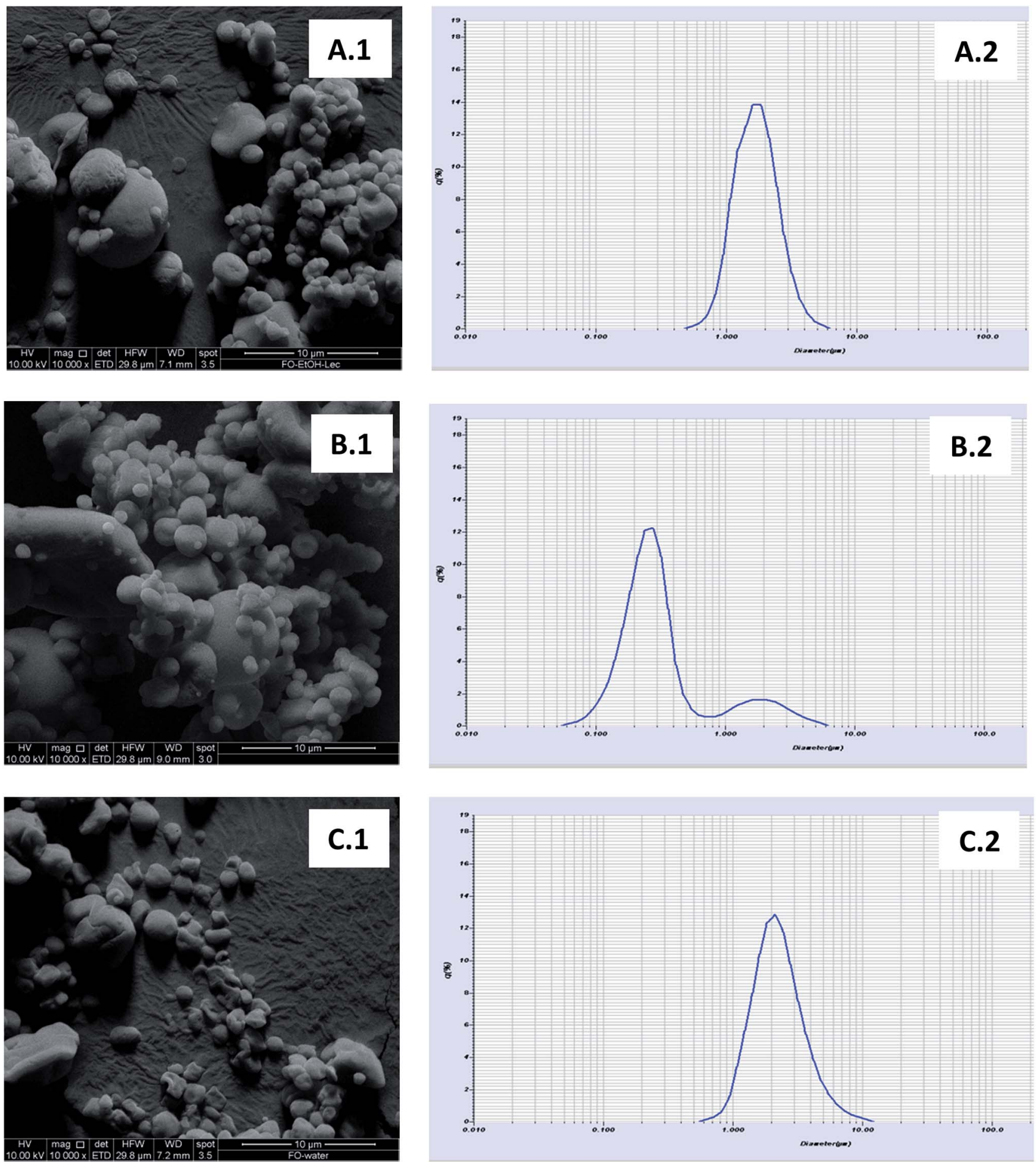

Fig. 2 Scanning electron microscopic photographs for FO-EtOH-Lec (A.1), FO-EtOH (B.1) and FO-W-Lec (C.1), and particle size distribution for $\mathrm{FO}-\mathrm{EtOH}$-Lec (A.2), FO-EtOH (B.2) and FO-W-Lec (C.2). 

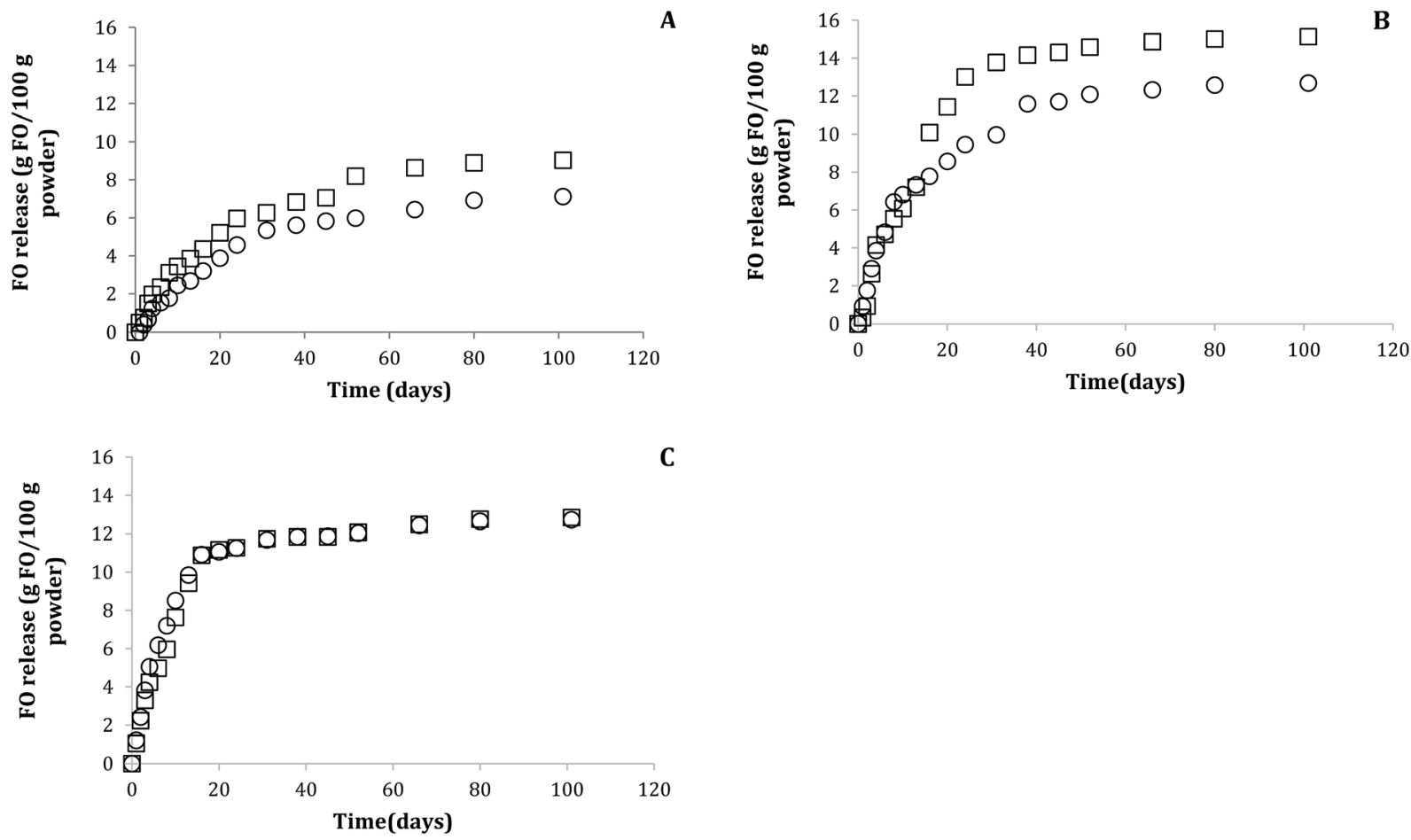

C

Fig. 3 FO release profile from FO microparticles obtained under optimal conditions (FO-EtOH-Lec) (A), FO-EtOH (B) and FO-W-Lec (C), in aqueous models $(\mathrm{O} \mathrm{pH} 4.6, \square \mathrm{pH} 6.5)$ at $30^{\circ} \mathrm{C}$.

particle shrinkage due to the high inlet gas temperature $\left(200^{\circ} \mathrm{C}\right)$ during the spray-drying process.

A unimodal particle size distribution was found in the FOmicroparticle systems with lecithin, with sizes ranging from $0.5 \mu \mathrm{m}$ to $6 \mu \mathrm{m}$ and from $0.5 \mu \mathrm{m}$ to approximately $10 \mu \mathrm{m}$ in FOEtOH-Lec and FO-W-Lec, respectively (Fig. 2A.2 and 2C.2). Particles with higher sizes in FO-W-Lec system also led to higher $D_{(4,3)}$ values $(2.43 \mu \mathrm{m}$ vs. $1.80 \mu \mathrm{m}$ obtained for FO-EtOH-Lec; Table 3). In the case of the FO-EtOH system, a bimodal particle size distribution was found, with a dominant population ranging from 0.05 to $0.8 \mu \mathrm{m}$ and a small population between 0.8 and $6 \mu \mathrm{m}$ (Fig. 2B.2). Furthermore, $D_{(4,3)}$ value was lower than in the FO-microparticle systems with lecithin (0.54 $\mu \mathrm{m}$; Table 3). This particle size distribution can be also observed in the SEM photographs (Fig. 2B.1). Therefore, smaller FO microparticles were obtained when the FO was incorporated as oil-in-ethanol dispersion (without emulsifier).

\subsection{Release of fish oil from FO microparticles}

The FO release profile in aqueous model ( $\mathrm{pH} 4.6$ and 6.5) showed one phase (Fig. 3), where the release percentage was lower than $16 \mathrm{~g} \mathrm{FO} / 100 \mathrm{~g}$ power for all FO-systems during the studied period at $30{ }^{\circ} \mathrm{C}$. This FO released corresponded only to surface FO and release of encapsulated FO was not observed, in spite of the encapsulation mechanism could be different due to presence of lecithin and in agreement with the low affinity of the hydrophobic triglycerides for aqueous medium. The data

Table 4 Polar compounds in oils extracted from FO-W-Lec, FO-EtOH and FO-EtOH-Lec microparticles ${ }^{a}$

\begin{tabular}{|c|c|c|c|c|c|c|}
\hline \multirow[b]{2}{*}{ Polar compounds ( $\%$ on oil extracted) } & \multicolumn{2}{|l|}{ FO-W-Lec } & \multicolumn{2}{|l|}{ FO-EtOH } & \multicolumn{2}{|l|}{ FO-EtOH-Lec } \\
\hline & Surface & Encapsulated & Surface & Encapsulated & Surface & Encapsulated \\
\hline TG dimers & $1.6 \pm 0.00^{1 \mathrm{a}}$ & $1.4 \pm 0.01^{2 \mathrm{C}}$ & $1.2 \pm 0.08^{2 \mathrm{~b}}$ & $1.7 \pm 0.02^{1 \mathrm{~A}}$ & $0.7 \pm 0.02^{2 \mathrm{c}}$ & $1.2 \pm 0.03^{1 \mathrm{D}}$ \\
\hline Oxidized TG monomers & $4.8 \pm 0.13^{1 \mathrm{~cd}}$ & $3.4 \pm 0.01^{2 \mathrm{E}}$ & $6.9 \pm 0.13^{2 \mathrm{a}}$ & $7.6 \pm 0.08^{1 \mathrm{~A}}$ & $4.5 \pm 0.08^{1 \mathrm{~d}}$ & $4.0 \pm 0.03^{2 \mathrm{D}}$ \\
\hline Diacylglycerols & $3.0 \pm 0.00^{2 \mathrm{~d}}$ & $4.1 \pm 0.07^{1 \mathrm{~A}}$ & $6.6 \pm 0.12^{1 \mathrm{~b}}$ & $2.5 \pm 0.01^{2 \mathrm{D}}$ & $4.4 \pm 0.03^{1 \mathrm{c}}$ & $2.7 \pm 0.00^{2 \mathrm{CD}}$ \\
\hline Total polar compounds & $10.47 \pm 0.08^{1 \mathrm{c}}$ & $10.3 \pm 0.05^{1 \mathrm{C}}$ & $16.0 \pm 0.26^{1 \mathrm{a}}$ & $13.3 \pm 0.10^{2 \mathrm{~A}}$ & $10.7 \pm 0.25^{1 \mathrm{c}}$ & $9.3 \pm 0.07^{2 \mathrm{D}}$ \\
\hline
\end{tabular}

${ }^{a}$ Different numbers in the same microparticle system mean significant differences between surface and encapsulated oil fractions $(n=3, p \leq 0.05)$. Different lower-case letters in each row mean significant differences between encapsulated oil fractions $(n=3, p \leq 0.05)$. Different upper-case letters in each row mean significant differences between encapsulated oil fractions ( $n=3, p \leq 0.05)$. TG: triacylglycerol. 
were fitted to Higuchi mathematical model, with correlation coefficient over 0.97 in all the systems, showing Fickian diffusion because only surface FO was released. The FO-W-Lec $(0.030$ \pm 0.003 days $^{0.5}$ and $0.029 \pm 0.001$ days $^{0.5}$ at $\mathrm{pH} 4.6$ and 6.5, respectively) and FO-EtOH $\left(0.020 \pm 0.002\right.$ days $^{0.5}$ and $0.027 \pm$ 0.012 days $^{0.5}$ at $\mathrm{pH} 4.6$ and 6.5 , respectively) systems showed the highest release rate constants in both aqueous media, followed by FO-EtOH-Lec $\left(0.013 \pm 0.003\right.$ days $^{0.5}$ and $0.012 \pm 0.001$ days $^{0.5}$ at $\mathrm{pH} 4.6$ and 6.5, respectively).

\subsection{Stability of microencapsulated fish-oil during storage}

Table 4 shows the results obtained for polar compounds, including total level and distribution in different groups of oxidation compounds and hydrolysis products, in surface and
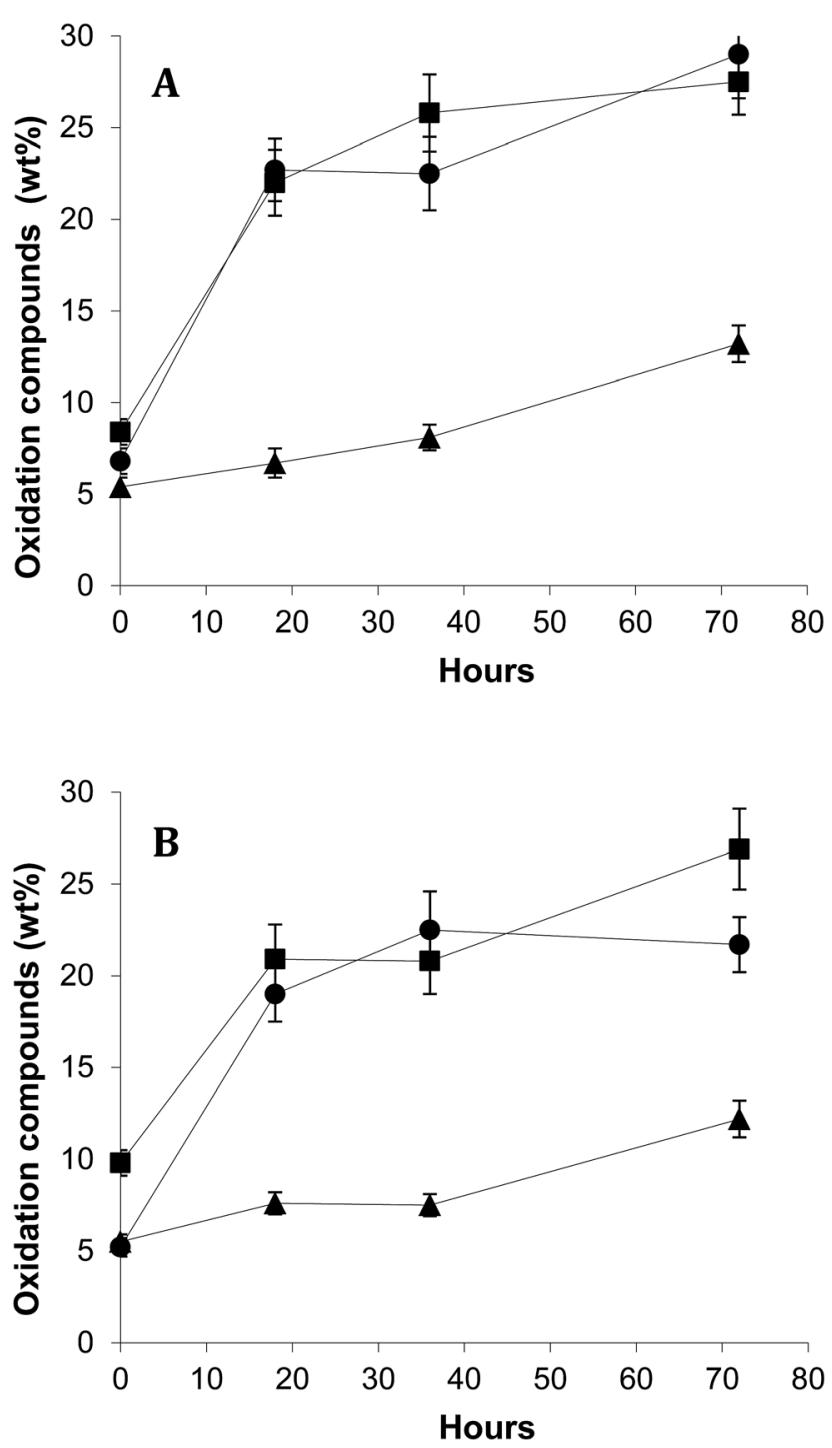

Fig. 4 Time-course of formation of total oxidation compounds in (A) surface and (B) encapsulated oil fractions of fish oil (FO) microparticles prepared with water-lecithin (circles, FO-W-Lec), ethanol (squares, $\mathrm{FO}-\mathrm{EtOH}$ ), and ethanol-lecithin (triangles, FO-EtOH-Lec), stored at $40{ }^{\circ} \mathrm{C}$ in the dark. Values correspond to means of triplicate samples and error bars to standard deviations. encapsulated fractions of the oils extracted from initial microparticles. This analytical approach has been successfully applied to quantitate oxidation compounds in microencapsulated oils and proved to be more complete and sensitive than determinations traditionally used, such as TBARS or peroxide value. ${ }^{17,23,24}$ Results showed that, even though values obtained among surface and encapsulated oil fractions and among microparticles systems were very close, it was clear that preparation of microparticles with ethanol using lecithin led to lower levels of oxidation compounds, especially regarding dimers and polymers.

Fig. 4 shows time-course of formation of total oxidation compounds (oxidized triacylglycerol monomers plus triacylglycerol dimers and polymers) in surface and encapsulated oil fractions during oxidation at $40{ }^{\circ} \mathrm{C}$ in the dark. Oxidized triacylglycerol monomers include monomeric triacylglycerols with one or more oxygenated functions, mostly hydroperoxides during the early oxidation stage or epoxides, alcohols and ketones during advanced oxidation stages. Dimers and polymers start forming once oxidation is accelerated. Therefore, global quantitation of oxidized triacylglycerol monomers, dimers and polymers provides a complete measurement of the oxidation level throughout the entire oxidation process. ${ }^{24}$ Results showed remarkably lower oxidation for FO-EtOH-Lec microparticles both in surface and encapsulated oil fractions throughout oxidation. After 72 hours, values higher than $25 \%$ of oxidation compounds had been reached in FO-W-Lec and FOEtOH microparticles, in marked contrast with only $12-13 \%$ in the case of FO-EtOH-Lec samples. Evaluation of the levels of EPA and DHA remaining after storage for 72 hours at $40{ }^{\circ} \mathrm{C}$ in the dark, revealed that FO-EtOH-Lec microparticles contained $32 \mathrm{mg} \mathrm{g}^{-1}$ microparticle versus $27.7 \mathrm{mg} \mathrm{g}^{-1}$ and only $19 \mathrm{mg} \mathrm{g}^{-1}$ in FO-EtOH and FO-W-Lec microparticles, respectively.

At lower temperature, $5{ }^{\circ} \mathrm{C}$ (Fig. 5), results showed consistently the highest stability for FO-EtOH-Lec microparticles. In this case, polymers plus dimers in total microencapsulated oil were determined after 5 months-storage. As it is well-known, polymerization compounds increase rapidly in FO even at low

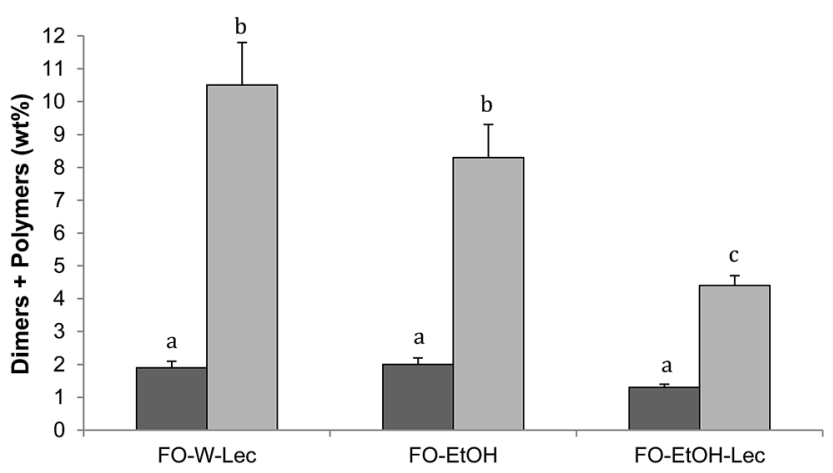

Fig. 5 Content of triglyceride dimers and polymers of total oil extracted from $\mathrm{FO}$ microparticles prepared with water-lecithin (FO$\mathrm{W}$-Lec), ethanol (FO-EtOH) and ethanol-lecithin (FO-EtOH-Lec), at initial time (black bars) and after 5 months-(grey bars) of storage at $5{ }^{\circ} \mathrm{C}$ in the dark. Values correspond to means of triplicate samples and error bars to standard deviations. 
temperature due to their considerable content in polyunsaturated fatty acids, which are highly susceptible to oxidation. ${ }^{17,25}$ The results obtained in the assays carried out on oxidative stability seem not to be associated to differences in particle size distribution or EE between microparticles.

\section{Conclusions}

For FO-microparticles with lecithin, the replacement of water by ethanol contributed to the significantly highest EE and stability of FO. The lower FO-oxidation for FO-EtOH-Lec may be related to the substantially lower inlet gas temperature, the use of nitrogen as drying gas and the physical barrier that lecithin forms around the oil droplets to the oxygen flow.

\section{Conflicts of interest}

There are not conflicts to declare.

\section{Acknowledgements}

The authors acknowledge the FONDECYT project Grant No. 1151224 (CONICYT, Chile).

\section{References}

1 J. Din, D. E. Newby and A. D. Flapan, Omega 3 fatty acids and the cardiovascular disease-fishing for a natural treatment, BMJ, 2004, 328, 30-35.

2 E. Arab-Tehrany, M. Jacquot, C. Gaiani, M. Imran, S. Desobry and M. Linder, Beneficial effects and oxidative stability of omega-3 long-chain polyunsaturated fatty acids, Trends Food Sci. Technol., 2012, 25, 24-33.

3 J. Kralovec, S. Zhang, W. Zhang and C. Barrow, A review of the progress in enzymatic concentration and microencapsulation of omega-3 rich oil from fish and microbial sources, Food Chem., 2012, 131, 639-644.

4 M. Aghbashlo, H. Mobli, A. Madadlou and S. Rafiee, Fish oil microencapsulation as influenced by spray dryer operational variables, Int. J. Food Sci. Technol., 2013, 48, 1707-1713.

5 M. Aghbashlo, H. Mobli, S. Rafiee and A. Madadlou, Energy and exergy analyses of the spray drying process of fish oil microencapsulation, Biosystems Engineering, 2012, 111, 229-241.

6 S. Palavarapu, C. M. Oliver, S. Ajlouni and M. A. Augustin, Physicochemical characterization and oxidative stability of fish oil and fish oil-extra virgin oil microencapsulated by sugar beet pectin, Food Chem., 2011, 127, 1694-1705.

7 L. A. Shaw, D. J. McClements and E. A. Decker, Spray-dried multilayered emulsions as a delivery method for w-3 fatty acids into food systems, J. Agric. Food Chem., 2007, 55, 3112-3119.

8 A. Gharsallaoui, G. Rouaut, O. Chambin, A. Voilley and R. Saurel, Applications of spray-drying in microencapsulation of food ingredients: An overview, Food Res. Int., 2007, 10, 1107-1121.
9 M. Aghbashlo, H. Mobli, A. Madadlou and S. Rafiee, Influence of wall material and Inlet Drying Air Temperature on the Microencapsulation of Fish Oil by Spray Drying, Food Bioprocess Technol., 2013b, 6, 1561-1569.

10 S. Drusch, Sugar beet pectin: A novel emulsifying wall component for microencapsulation of lipophilic food ingredients by spray-drying, Food Hydrocolloids, 2007, 21, 1223-1228.

11 S. M. Jafari, E. Assadpoor, B. Bhandari and Y. He, Nanoparticle encapsulation of fish oil by spray drying, Food Res. Int., 2008, 41, 172-183.

12 K. Gilani, A. R. Najafabadi, M. Bagui and M. Rafiee-Tehrani, The effect of water to ethanol feed ratio on physical properties and aerosolization behavior of spray dried cromolyn sodium particles, J. Pharm. Sci., 2005, 94, 10481058.

13 AOAC, Official Methods of Analysis of AOAC International, Gaythersburg, USA, 15th edn, 1990.

14 AOCS, Determination of cis-, trans-, saturated, monounsaturated, and polyunsaturated fatty acids in extracted fats by capillary GLC, Official method Ce1j-08, 2007.

15 Y. Cai and H. Corke, Production and properties of spraydried Amaranthus betacyanin pigments, J. Food Sci., 2000, 65, 1248-1252.

16 T. Higuchi, Mechanism of sustained-action medication. Theoretical analysis of rate of release of solid drugs dispersed in solid matrices, J. Pharm. Sci., 1963, 52, 11451149.

17 G. Márquez-Ruiz, J. Velasco and M. C. Dobarganes, Evaluation of oxidation in dried microencapsulated fish oil by a combination of adsorption and size exclusion chromatography, Eur. Food Res. Technol., 2000, 211, 13-18.

18 G. Márquez-Ruiz, N. Jorge, M. Martîn-Polvillo and M. C. Dobarganes, Rapid, quantitative determination of polar compounds in fats and oils by solid-phase extraction and exclusion chromatography using monoestearin as internal standard, J. Chromatogr., 1996, 749, 55-60.

19 C. Encina, C. Vergara, B. Giménez, F. Oyarzun-Ampuero and P. Robert, Conventional spray-drying and future trends for the microencapsulation of fish oil, Trends Food Sci. Technol., 2016, 56, 46-60.

20 Q. Xu, M. Nakajima, H. Nabetani, S. Ichikawa and X. Liu, Factors affecting the properties of etanol-in-oil emulsions, Food Sci. Technol. Res., 2002, 8(1), 36-41.

21 A. G. Gaonkar, Interfacial tensions of vegetable oil/water systems: effect of oil purification, J. Am. Oil Chem. Soc., 1989, 66(8), 1090-1092.

22 K. E. Patrick, Y. Lv, V. Muhamyankaka, O. Denis, I. S. B. Ntsama and X. Zhang, Development of EPA-DHA microparticles supplemented probiotic fermented milk, Akademik Gıda ${ }^{\circledR}$ (Academic Journal Food), 2013, vol. 11, pp. 6-15.

23 G. Márquez-Ruiz, J. Velasco and M. C. Dobarganes, Oxidation in dried microencapsulated oils, in Lipid Oxidation Pathways, ed. A. Kamal-Eldin, American Oil Chemists Society, Champaign, IL, USA, 2003, pp. 245-264. 
24 G. Márquez-Ruiz and M. C. Dobarganes, Analysis of nonvolatile lipid oxidation compounds by high-performance size-exclusion chromatography, in Analysis of Lipid Oxidation, ed. A. Kamal-Eldin and J. Pokorny, American Oil Chemists Society, Champaign, IL, USA, 2005, pp. 40-69.
25 J. Velasco, S. Marmesat, M. C. Dobarganes and G. MárquezRuiz, Heterogeneous aspects of lipid oxidation in dried microencapsulated oils, J. Agric. Food Chem., 2006, 54, 1722-1729. 